\title{
Mick Horton: 'Empathy for your patients is the most important trait a GDP needs'
}

Interview by Ruth Doherty

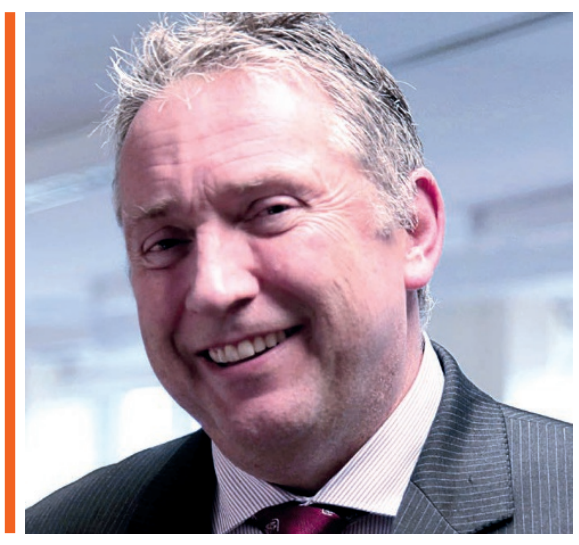

Why does FGDP(UK) need to be independent from the Royal College of Surgeons (RCS)?

We've got to ensure that dentistry has an appropriate standing alongside other healthcare professions, and most of those other professions already have their own colleges.

In order for us to cultivate confidence in our profession we need to be seen to be leading it via our guidelines, standards and education to improve the quality of care that we give to our patients. We can't do that as effectively when somebody else may be directing our purpose; sometimes we do have different priorities to the RCS. While both organisations exist to improve the care that's provided to patients, we often need to do that in a slightly different way to each other.

A separate college to represent dentistry was first put forward over a hundred years ago so it's long overdue. Even when FGDP was set up in 1992, one of the stated intentions was that it would become an autonomous body. So 25 years down the line it's very appropriate for us to now spread our wings. The change will allow us the freedom to truly represent the dental profession as an academic body, without being a subdivision of a different body.

The biggest thing that I can see occurring over the next few years is the rapid evolution of the way that dentistry is delivered. I'm not convinced that our current structure allows

Dr Mick Horton is the outgoing Dean of the Faculty of General Dental Practice (FGDP[UK]), the ninth Dean since its founding in 1992. In his time as Dean, Mick presided over the decision to establish FGDP(UK) as an independent college for general dental practice. The new organisation aims to provide a collegiate home and professional standing for GDPs and all members of the general dental team. Mick qualified from Manchester University in 1986. In 1992, he purchased a mixed NHS/private practice in Caergwrle, north Wales. His experience includes being a member of the Welsh Dental Committee, 19 years as the chair of his local dental committee and 10 years as the vice chair of his local health board.

us to adapt to the changing environment quite as quickly as we would be able to if we were a separate organisation. As a separate college we can be much more responsive.

\section{Can FGDP(UK) survive on its own?}

I would suggest we already do. Although we are currently a part of the RCS, we organise our financial structure, our membership, our courses, our examinations as a separate body anyway, just under the umbrella of the larger of career pathways, ensuring the quality of training, implementing quality standards or just providing support and advice. We see ourselves working alongside some of the other key organisations in dentistry because I think we all have a lot to offer. For too long as a profession we have divided our different organisations a little bit too thinly and it's probably an excellent time to look to work together more for the good of the patients and of course the profession.

\section{'We have to show that we have the professional skills and abilities to make clear that we can self-regulate...'}

organisation. In terms of being profitable and being able to sustain ourselves, we already do that. I think we have some of the best courses in the world and I have no doubt that with an additional push we will only grow as an organisation.

\section{What will FGDP(UK) be doing in five years' time?}

We would hope and expect to have had a demonstrable effect on all professionals, rather than just a small group of them; whether that is in relation to the development
I think in the future post-graduate education will be a more structured part of people's career pathways. At the moment organisations, such as FGDP(UK), wait for people to come to them to say they have an interest in membership and examination and we need to be more proactive in making these part of a structured pathway for career development. I think there is value in following a pathway that will see GDPs progress throughout their career terminating in higher qualifications or awards, such as fellowships. 
What has your role as FGDP(UK) Dean since 2015 involved?

A million things. The official role is to be the public face of the Faculty. The Board are there to give their strategic decisions and I follow through these to ensure the wishes of the Board are enacted by the whole team in the office here and in our divisions.

Then there are also side roles in which I sit on a number of key bodies, with the BDA or GDPC, often working with the chief dental officers across the UK. We meet with other local bodies that may have an interest in dentistry, eg the defence unions, educational
For many years, I have been calling for an anonymous reporting structure to be established through which incidents can be reported centrally by dentists without fear of reprisal. The value in that reporting is understanding more about what tends to happen in practice so that we can prevent it or encourage it to happen again, as appropriate. The value isn't in knowing who did what to whom, the value is in knowing why.

We under-report minor events because we are scared of reprisal but I feel if we understood that these events were common, they would become less of an outlier, and part

\section{'If we all stand still and the world moves past, then we are going backwards!'}

institutions and the regulators. It's more important to ensure the profession has a breadth of voices at those meetings rather than a single individual who may just have one point of view.

My working week as Dean was very busy - I worked about four days a week in practice, attended meetings two days a week, then paperwork seven nights a week. I get to spend time my family rarely at the moment! I'm fortunate in that I survive on about four hours sleep a night.

I love practising dentistry - I still get a huge kick out of fitting a bridge or dentures or even just seeing a young child sitting in the dental chair for the first time with a cheeky grin! I've been in my current practice for over 25 years and I'm now seeing the children of the children who were born when I started.

\section{What do you feel are the three main challenges facing GDPs in the UK now?} I would say, firstly, that when I speak to both early careers dentists and more mature dentists, like myself, many say we are over-regulated. I think that to combat this we have to show that we have the professional skills and abilities to make clear that we can self-regulate. In the absence of that, the regulator has no choice but to ask for verification and sometimes that is perceived as over-regulation. Now I'm not saying that there isn't over-regulation but perhaps we might bring it on ourselves occasionally by not self-regulating or showing that we are able to. of that treatment rather than a 'significant incident.' When you look in the available data, for example trying to find out how often there is a fracture of a file in a root canal, it is incredibly difficult to get that information. When it happens we inform the patient and tell them it happens 'occasionally' but we don't know how often it really occurs. It would be so much more useful if we could actually put a figure on that, eg from our reports it occurs in ' $60 \%$ of cases'.

The second challenge has to be running a practice. I bought my practice in 1992, and I have to say it was a pleasant life at the time and I enjoyed coming to work. I won't say I don't enjoy coming to work now but there are challenges every single day that were not necessarily there 20 years ago. The current environment of reducing profits while the expectations of the commissioners, regulators and patients appear to be rising exponentially does tend to put undue pressure on all the profession, but particularly practice owners.

We appear to be very good at responding to challenges but we are not particularly next few hours, days or even weeks chasing around and trying to deal with these issues. I still have those Monday morning doorstep moments the same as everybody else but I do think that somehow as a profession we need to look at how we manage those more effectively in the future. I think part of the problem within dentistry is that we have to work within someone else's framework which is rather dictatorial. We need to re-introduce some flexibility and common sense back into the system.

The third challenge is to do with professionalism. My perception is that our professionalism is being whittled away, through others reporting what it is we don't do well, how much money it costs to visit the dentist, the queues, the problems within dentistry etc. The perception of the public is that they pay a lot of money for not a very good service, and the reality is that virtually all of us provide an exceptional service through long hours of the day, working incredibly hard and at a relatively good value-formoney rate. So I just think that we need to use advocates to improve this perception of us as a profession.

\section{How can the Faculty help GDPs to overcome these challenges?}

With the problems around professionalism and public perception, as a new college we will need to act as an advocate, in conjunction with the BDA and other organisations, to release joint statements where appropriate to augment our voice. We are all saying the same thing so if we start to show a united front we will regain our professionalism. We don't do our profession any favours by arguing amongst ourselves rather than putting a consistent message across.

With regard to reporting incidents, we are working closely with other organisations to develop a reporting tool. It will be a big challenge to see if we can make that system anonymous or to ensure in some other way

\section{'The value isn't in knowing who did what to whom, the value is in knowing why.'}

good at spotting those challenges before they actually happen. We wait until they jump on our doorstep on a Monday morning, for example a patient escalating a minor question using legislative means when this is not necessary, and then we have to spend the that there is no concern around a threat of reprisal for those reporting. Certainly, that is how I would wish it to be.

In terms of running practices, at the FGDP(UK) we certainly recognise that the profession needs leadership and management 
training and this is not being comprehensively provided at the moment. We all leave university with a high level of theoretical knowledge, a moderate level of practical skills and little or no awareness of how to manage ourselves or a practice. As an undergraduate it's difficult to focus on taking in that knowledge when you

\section{Why did you choose dentistry as a career?}

I've always been fascinated by science, right from the start. When we were young my brothers had comics and I had the Book of Knowledge. I have always been amazed by the human body and how it worked, so it

\section{'I am calling for an anonymous reporting structure for reporting incidents without fear of reprisal'}

are already trying to learn so many clinical skills. I think there is an absolute need to provide leadership and management training as part of a career structure, and FGDP(UK) are in the process now of developing a programme to deliver this.

\section{Obviously the FGDP is heavily involved in producing guidance for GDPs. However, there is an argument that increased levels of guidance is chipping away the autonomy of the dentist as a professional. Is this a worry for you?}

If we, as dentists, say that we know best and we don't need guidance, we act with an air of arrogance and with no evidence base whatsoever. However, on the flipside, if we produce standards that constantly state there's only one direction of travel then I agree that reduces autonomy and professionalism.

In the case of the Faculty, we produce guidelines and standards that recognise patients, treatments and professional decisions all play a part in the working environment. I think the best example of this is our Clinical Examination and Record Keeping guidelines released in 2016, in which we set out the way we want to deliver our guidelines from now on, using an A, B, C system - Aspirational, Basic, and Conditional, depending on the patient. That allows the professional to make an individual decision on treatment based on the interest of the patient, the dentist and the circumstances. The professional should always be the one to make the decision depending on those circumstances. The guidelines are there to help you in defending the decisions you take with your patients, rather than dictating decisions. must have come from there. I think you need to be that type of person to be a healthcare professional. It's very difficult to do anything within the healthcare profession if you don't have a commitment to it. To enter it because someone else tells you to is not the way to go and those people tend not to last very long in the profession.

\section{Do you ever have a plan B?}

I've got a passion for music and art, so in my early teens I was torn between going to music college, art school or studying dentistry. In my mid-teens I often went to art exhibitions and at one of these I got talking to one of the artists. He gave me the best bit of advice anyone has ever given me which was: 'Music and art are wonderful hobbies to have while you practise dentistry!' That made up my mind and I've never looked back.

\section{What do you think are the most important traits for a GDP to have?}

Empathy for your patients is probably the biggest one. If you don't understand where you patients are coming from then it's very difficult for you to know where to take them to. You need to be able to understand their emotions.

You also need a huge sense of realism - especially for some of the issues around contracts and the like that face us all these days.

You need an absolute thirst for knowledge and we need to all recognise that if we all stand still and the world moves past, then we are going backwards! Gone are the days were professionals never attended courses or read books; a BDS on the day you qualified is not enough for a lifetime of a career.
We as dentists also need very broad shoulders because there are times where everything seems to conspire against us. However, if we persevere with things then I honestly think this is the most rewarding profession you will ever get.

\section{What do you say to someone who feels stuck in their career?}

That's where I would suggest someone needs mentoring. One of the areas that we have discussed is trying to develop local champions and mentors who could take professionals who need/want that help by the hand to help lead them through that pathway or onto that pathway so they can start that development themselves.

We all need to recognise that not everyone wants to sprint. We are developing the new college's educational pathway so people can go at their own pace, and get on and off when necessary. They will not be on a conveyor belt going at 100 miles an hour unless they want to be!

Readers can find some of the Clinical examination \& record-keeping guidance mentioned by Mick in this interview in the BDJ:

- Clinical examination \& record-keeping: Part 1: Dental records:

https://www.nature.com/articles/

sj.bdj.2017.984

- Clinical examination \& record-keeping:

Part 2: History taking:

https://www.nature.com/articles/

sj.bdj.2017.989

- Clinical examination \& record-keeping:

Part 3: Electronic records:

https://www.nature.com/articles/

sj.bdj.2017.994

The complete guidance is available from $F G D P(U K)$ at: www.fgdp.org.uk/ guidance-standards

The new Dean of FGDP(UK), who began in post on the 15 June 2018, is Dr lan Mills. More info at https://www.fgdp.org.uk/ news/ian-mills-be-next-dean-fgdpuk. 